\title{
Faculty Rankings and Management of Human Capital of a University
}

\author{
Olga Saginova ${ }^{1}$ \\ Nadezhda Zavyalova ${ }^{1}$ \\ Irina Skorobogatykh ${ }^{2}$ \\ Olga Grishina ${ }^{3}$ \\ Zhanna Musatova² \\ ${ }^{1}$ Department of Entrepreneurship and Logistics, Plekhanov Russian University of Economics \\ 2 Department of Marketing, Plekhanov Russian University of Economics \\ 3 Vice-Rector of Education and Informatisation, Plekhanov Russian University of Economics \\ Correspondence: Irina Skorobogatykh, Department of Marketing, Plekhanov Russian University of Economics \\ Moscow, Russian Federation; E-mail: Skorobogatykh.II@rea.ru
}

Doi:10.5901/mjss.2015.v6n5s4p465

\begin{abstract}
The paper analyzes current issues of managing human capital of a modern university including personnel planning and development, recruitment, talent management, and their impact on the university image and reputation. The paper reports on the research performed at the Plekhanov Russian University of Economics regarding development of a system of indicators for faculty ranking. The research results are assessed against increased competition in the higher education sector, the new criteria for evaluation of the effectiveness of Russian universities, and the need to differentiate faculties' remuneration depending on their teaching and research performance.
\end{abstract}

Keywords: Human capital, university, knowledge economy, competitiveness, talent management, personnel recruitment, university and faculty rankings, performance assessment

\section{Introduction}

The most important external factor influencing the system of higher education currently is the emergence and further development of knowledge economy. The concept first introduced by Fritz Machlup (1996) is now used to define the decisive role of knowledge in economy and the role of knowledge production as the source of economic development. Knowledge economy is characterized by the growing importance of knowledge creation and distribution for economic development (Forey, 2004). With the development of globalization, the importance of knowledge as a factor of economic development and competitiveness of countries and regions has increased (Drucker, 1985; Grant, 1991). The knowledge economy concept is wider than that of "digital" or "new" economy (Malhotra, 2003), as it embraces not only processes in separate sectors, but the entire economy. Knowledge becomes a source of development of all industries and sectors. Key characteristics of knowledge economy are given in Table 1.

Knowledge becomes a product traded for profit, and intellectual capital becomes a factor of innovations. Intellectual capital usually is viewed as a combination of three elements: human capital, structural capital, and consumer capital. Human capital includes collective knowledge, skills, and competences accumulated by the organization's staff. Structural capital provides an organizational structure for it. Consumer capital includes relationships with the organization's consumers and clients, strategic partners and shareholders. Human capital was researched by $F$. Machlup, T. Schultz, and G. S. Becker who received the Nobel Prize for his "Human Capital" book written in 1964. 
Table 1. Knowledge economy characteristics

\begin{tabular}{ll}
\hline Characteristics & Definition \\
\hline Demassification & $\begin{array}{l}\text { Decreased importance of labor, capital and materials concentration in one place } \\
\text { (massification) }\end{array}$ \\
\hline Cross-border organization/ distance employees & $\begin{array}{l}\text { Knowledge crosses the borders of organizations, industries, and countries; } \\
\text { organizations are more independent of time and space, labor can be provided } \\
\text { remotely }\end{array}$ \\
\hline Virtualization & Virtual teams, auctions, corporations, and other physical concepts \\
\hline Interrelation/partnership/ networking & $\begin{array}{l}\text { Interrelations within and between organizations, partnership and cooperation of } \\
\text { organizations with their clients; partnership and networking between } \\
\text { organizations, neither of which has all necessary knowledge }\end{array}$ \\
\hline Personalization/mass customization & $\begin{array}{l}\text { Goods and services can meet individual needs of clients involved in the product } \\
\text { development and production, as their knowledge becomes part of product } \\
\text { specification }\end{array}$ \\
\hline Real-time processes & Real-time business, shorter product life cycles \\
\hline Consumers networks & Consumers interact and network globally \\
\hline
\end{tabular}

\section{Literature Review}

Human capital of educational organizations was analyzed primarily as an influence of education on its formation in a company, region, or country by developing necessary skills and competences (Rockoff, Jacob, Kane, \& Staiger, 2011; Khasawneh, 2011). Some authors analyzed the changes in the needs of students caused by the changes in labor conditions in knowledge economy (Machlup, 1996; Rockoff, Jacob, Kane, \& Staiger, 2011). There are numerous publications on the role of universities in developing specialists for innovative economy (Malhotra, 2003; Khasawneh, 2011). However, the number of publications concerning the role of human capital in the educational organization is much less, although some indicators of human capital development are used to measure universities' effectiveness (Shtykhno, 2012).

With these high requirements to a university's faculty, educational organizations face serious problems with human capital management. There are traditional issues of winning talented graduates from business trying to compete in salaries and better careers (Odden, 2011). Partially due to these traditional problems with staff recruitment and retention, universities have inefficient staff, often redundant and incompetent to deal with current teaching and research objectives (Metcalf, Rolfe, Stevens, \& Weale, 2005).

Beside recruitment, universities fail to develop effective systems of faculty remuneration and encouragement (Clotfelter, 1996; McElrath, 1992), which often do not depend on the faculty's teaching and research quality. The existing systems of faculty performance assessment are usually focused on collective efforts-they evaluate and rank departments and units of a university. Though in many cases, the quality of education is the result of collective efforts and department rankings stimulate groups and teams to improve their work, human capital management cannot ignore the influence of individual teachers, administrators, and researchers.

Human capital management includes personnel planning and recruitment. Personnel planning is based on modeling labor supply and is aimed to achieve optimal personnel number relevant to the university strategic and financial goals. Recruitment is part of personnel planning, and the best universities monitor the external market trends, such as demographic shifts, labor market demand, government regulation, as well as competition in the labor market.

Currently, in response to international universities rankings and the Russian Ministry of Education monitoring, universities try to attract and recruit faculty with high academic reputation. The Higher School of Economics, for example, started using the international recruitment approach, making jobs announcements accessible to outside candidates. Beside formal qualifications, the content of candidates' research is assessed through blind reviews of their research papers. Not all educational organizations are capable of conducting such an open application procedure, and high demand is needed for the announced vacancies. However, this experience shows a great potential for achieving higher academic results through well-planned faculty recruitment policies.

Use of employees' talents and capabilities is one of the important priorities of modern business. Talent management aims to optimize the performance and identification of potential talents inside the organization. Modern technologies, globalization, and increasing international competition change human capital perception. Market demand for talents makes talents an important asset of an organization, a strategically important and scarce resource (Serrat, 2010; Blass, 2007). Many organizations reconsider their talent management strategies at different stages of the 
employee life cycle. New innovative personnel development programs are needed for attracting and retaining a talent, including remuneration benefits and performance assessment (Malhotra, 2003; Odden, 2011). Universities use their websites and social media to promote a positive image and attract talents. New objectives and metrics, such as rate of return and profitability, which have never been used by universities as not-for-profit organizations, are now discussed and used to measure their performance. Talent management has not been part of university strategies either. Faculty have been recruited based on their CV, education, and experience, and then their administrative and research careers were promoted until they retire or leave to join another university. Attracting talents does not solve the problem, unless they are properly managed within the organization. Successful organizations not only succeed in attracting and retaining good staff, but also manage it to achieve strategic goals. This requires an effective personnel development system including a clear system of performance assessment.

\section{Faculty Assessment Research: Methodology and Sample}

Talent management in universities has two main results-quality of education and faculty performance (Odden, 2011). Higher education has a system to measure the quality of education and students' satisfaction, but faculty performance measurement is just being developed. This system is based on individual performance metrics for each faculty member in line with the university's strategic goals. A balanced scorecard system can identify the contribution of each faculty member into achieving strategic goals of a university. Almost each system of faculty assessment uses faculty rankings. These assessment programs are not easy to develop and introduce, and they can be resisted and rejected by faculty members who believe they should be trusted based on their proficiency and continuous professional engagement. Assessment also raises concerns about academic freedom. And still most universities work to develop delicate and complex assessment systems to improve faculty performance and improve the overall quality of university experience.

Initially, the research performed by a team of researchers from the Russian Plekhanov University of Economics in 2012-2014 had the main objective to develop requirements for the faculty reflecting the strategic goals of the university development, which could be used for faculty recruitment and performance assessment. The research methodology was based on desk research of faculty requirements systems of leading Russian and foreign universities complemented by indepth interviews with university representatives to clarify and supplement the results of the desk research. The samples for the research included universities from the USA and Europe, which had national and international accreditations and were comparable by size and specializations offered to the Plekhanov Russian University of Economics, and which were accessible for both desk and field research. During the initial stage of the research (2011-2012), five American and six European universities (from the UK, Germany, Austria, and France) were studied. Among Russian universities, we studied four Federal universities and three National Research universities. In addition to the universities, the research project team analyzed faculty requirements of the main international accreditation systems (AACSB, EQUIS, EPAS, AMBA).

The second part of the research (2013-2014) repeated the same methodology with almost the same sample universities and targeted to analyze the existing faculty assessment and ranking systems. Major university rankings were analyzed to identify indicators evaluating university faculty. The reason for this second stage was the thesis that collective rankings (of university departments and business units) individually do not ensure effective performance assessment and should be complemented by individual rankings of the faculty.

\section{Results and Discussion}

When faculty members' performance is assessed, several important facts have to be taken into account. All results can be measured by their quantity, quality, and costs. Quantitative parameters of assessment in education are not difficult. Costs are measured by the time spent to do a job and usually exist as a university's regulation. Qualitative assessment of faculty results is more difficult, like assessment of any other complex intellectual work. Methods of measuring quality and costs go beyond the scope of this paper, but it is important to say that rankings should not be based on one criterion only-the quantity of the work done, because these metrics are interrelated and an increase in one of them within the period measured can be accompanied by a decrease in others. An increase in the quantity can result in increased costs and decreased quality, or an increase in one type of work-papers published-can result in less attention paid to teaching and can lead to students' dissatisfaction with the quality of teaching. Thus, an improvement of faculty results can only be achieved if there are no negative changes in other aspects of its activity.

The research conducted showed that all universities used faculty assessment systems. While foreign universities used them to assess the individual contribution and performance of faculty members, Russian universities most often 
combined individual rankings with assessments of university departments' collective efforts and contributions. Results of collective rankings were used to distribute additional stimulation funding among university departments, while individual rankings were used to differentiate bonuses and remuneration based on the results achieved.

Assessment systems of foreign universities used information from student surveys, university databases, and faculty member's individual portfolios. Performance assessment periods in the US universities were linked to tenure track periods, and in European schools were linked either to the university accreditations or to faculty contract renewal periods. The maximum period was 6 years, and the minimum one was 1 year. The average period between assessments was 2-3 years. Individual faculty members were responsible for evidence collection and presentation, and the relevance and quality of the evidence provided was verified by appointed committee members. Many Russian universities researched used information systems to collect and process evidence, and relied on the individual entries of information into the system (for which faculty members were responsible), which was then approved by representatives of various functional departments of the university. For example, the number of publications was approved by the library service, teaching assignments-by the dean's offices, etc. In some Russian universities, most quantitative information was collected and stored in the system (number of publications, number of hours taught, number of conferences attended, etc.), while the portfolio-based approach collected actual copies of the publications, reviews of the classes visited, certificates of programs attended, etc. Many of the systems studied did not prioritize different types of activities, only used weights for measuring the results. That is why information collected was of very different importance and formats, and even with automated databases, the process was time-consuming and caused problems for the faculty.

The results of the research led the research team to conclude that there should be two types of information about faculty performance: The information about all faculty results can be collected and stored in the university's database. However, only those results should be used for performance assessment purposes, which are related to the university strategic objectives. The university database should be the main source of information about the faculty performance. Once entered using a uniform format, information can be used for many purposes by different university departments to avoid duplicated requests and time-consuming reporting procedures.

\section{Practical Outcome of the Research: The Plekhanov Faculty Ranking System}

Based on the research results, the requirements for the faculty performance assessment in the Plekhanov Russian University of Economics were formulated:

1) Faculty should be assessed only in key areas of activity important for the university's strategic development. These areas can change over time, reflecting the dynamic development of the university and external environment;

2) Indicators for performance assessment should not be numerous to focus the faculty attention on key metrics and save time and effort to collect the initial data;

3) The data should be collected from the existing reporting systems using uniform formats. This makes it possible to use the same data for different purposes without additional entry of information into the system.

The basis of the ranking system is formed by most important types of faculty activity. As most universities expect their faculty members to perform three main types of activity-research, teaching, and services, these are usually used to rank the faculty. However, a more detailed approach should be taken to specify those types of work that lead to achieving the strategic objectives of the university and promoting it in the university league tables.

For the Plekhanov University of Economics, the key areas (according to the strategic development plan) were the publication activity, internationalization, and participation in key events, with doing the required workload as a threshold measurement. Decomposition of faculty activities is shown in Figure 1. 


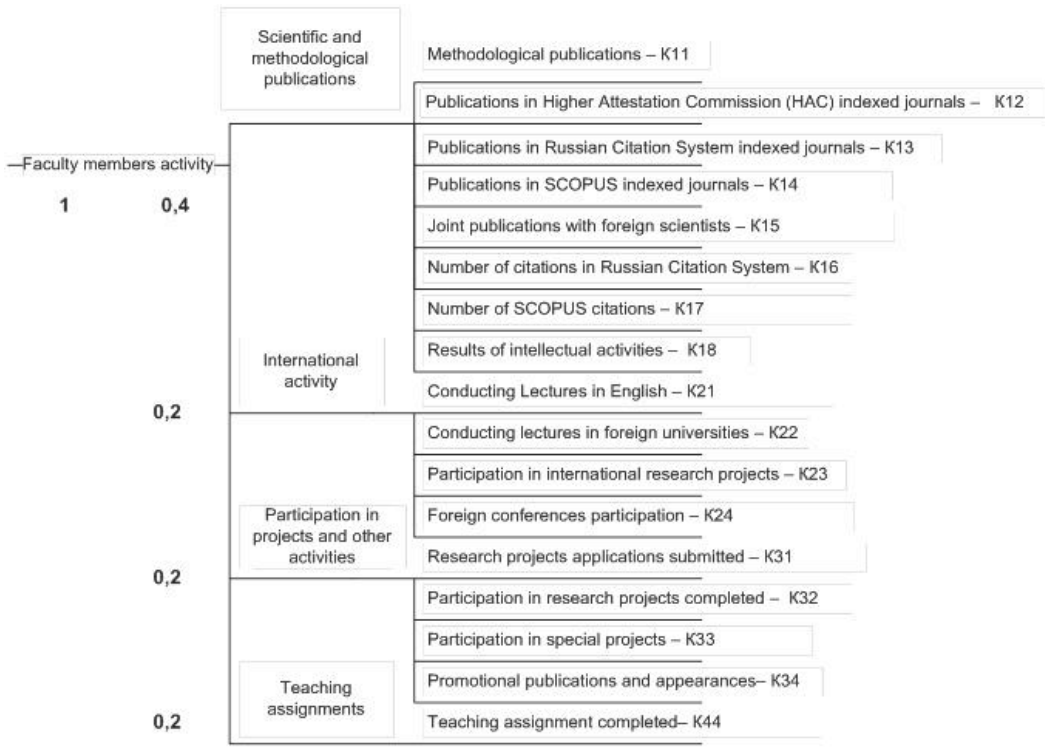

Figure 1. General decomposition of faculty activity types

When the objectives/solutions tree analysis was used, the following general rules were applied: (1) The height of the tree was defined by the requirement that the top level is represented by simple activities; (2) Each group includes activities of the same type; (3) each group includes a minimum number of activities, because the fewer activities the group contains, the more valid the assessed are, with all other conditions remaining unchanged. When quantitative assessment is made, the calculations include indicators of certain activities, not the activities themselves.

$K_{i j}$, where $i=1 \ldots n$ - the number of groups, $j=1 \ldots m$ - the number of criteria.

It is important that when an indicator is being identified, it should be the only indicator reflecting a certain feature of the activity. Besides the accessibility of information about the indicator was also taken into account. For example, when the publication activity was assessed, the number of publications was used, but not their volume. When all indicators are identified, the tree of objectives/solutions becomes a tree of indicators. Activities that could not be measured in physical units were measured in percentage.

When the system of indicators was being prepared, experts were given indicators in points to assess their maximum and minimum values. These experts' opinions evaluated the weight of each indicator among the others.

The irregular group importance index $W_{j}$ characterizes the activity related to $j$ activities included into the group $i=$ $1 \ldots n$, and $\sum_{j=1}^{m} W_{j}=A$, where $0<A<\infty, j=1 \ldots m$.

For the hierarchical structures of indicators, it is necessary to use regular group importance indices, calculated from the irregular as

$W_{j}^{\prime}=\frac{W_{j}}{\sum_{1}^{m} W_{j}}$,

The meaning of each index for each faculty member was formed as

$K_{i j}=\sum_{i=1}^{n} \sum_{j=1}^{m} W_{j}^{\prime} * R_{j}$

where $R_{j}$ is the- number of activities done in the $i^{\text {th }}$ group.

To compare, a model value of each index as the best in this group of faculty members was identified for each activity type. When the integral values were calculated and the results were visualized, the margin (acceptable) values were also identified for each activity. If model values were not known, the desired values to meet the strategic objectives were used.

To analyze the many different types of activities, OLAP technologies were used. The analysis revealed champions in a certain category and the activity type, as well as overall leaders in the department or university in the strategically important and relevant activities. This approach makes it possible to assess the faculty members' results taking into account their position and experience, as well as the contribution to achievement of the overall goals of the organization. 
Figure 2 presents the ranking of faculty members of one of the university departments in scientific publications.

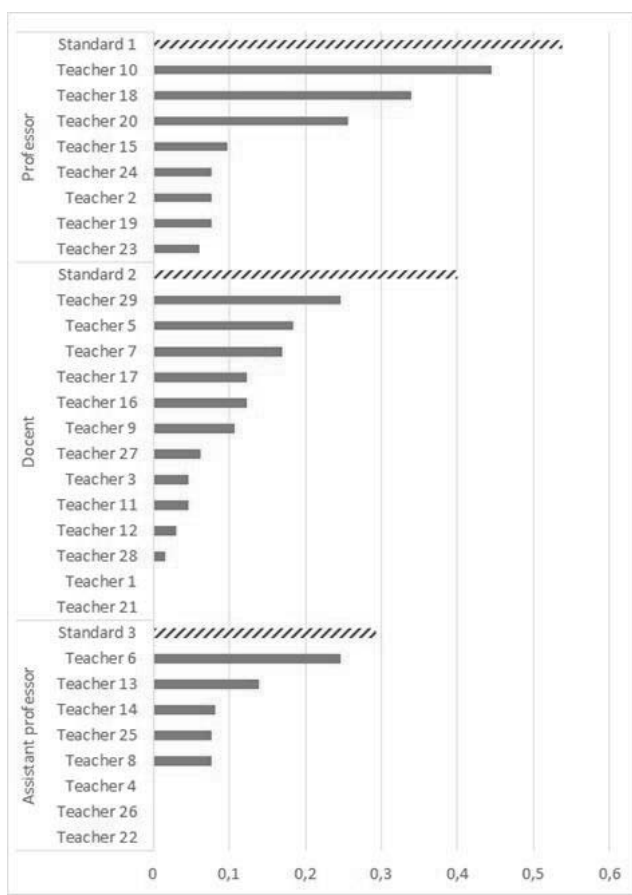

Figure 2. Faculty ranking in scientific publications

A further analysis can compare the publication activity for each faculty group (Figure 3). Individual ranking of faculty members is aimed at introducing uniform indicators to assess the performance in certain areas, building and maintaining faculty activity database, stimulating those types of activities, which ensure better quality of education and international promotion of the university, differentiating remuneration and bonuses to support the most effective faculty and assess the real contribution of each faculty member to the university results.

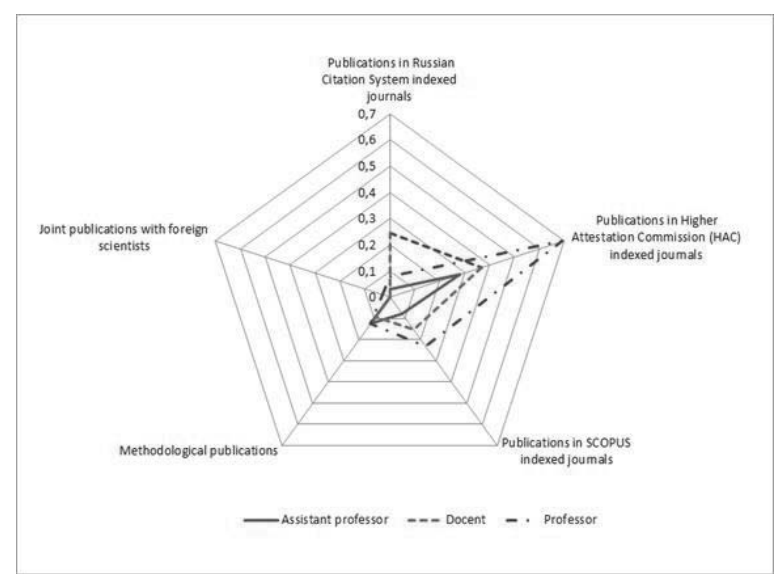

Figure 3. Publication activity analysis 
The indices used in ranking depend on the strategic goals of the university, so they are set for a certain period; indicators are announced at the beginning of this period and cannot be changed during this period.

\section{Conclusions and Further Research}

The research conducted showed the importance, benefits, and limitations of existing systems of faculty performance assessment, identified key activity areas to be assessed, allowed to formulate the individual and collective effort needed to collect initial data and feed it into the system. The benefits of individual ranking include the opportunities to use it for differentiating faculty remuneration, focusing the faculty efforts on the key strategic goals of a university, and attracting and retaining the most effective faculty.

The predominance of quantitative indices reflects the requirements of both international and national accreditation and monitoring systems. However, there are three main criteria of assessment: quantitative, qualitative, and cost-related measures. It is equally important to measure the contribution of faculty to achieving university's objectives within the given time-periods and budgets. If it is necessary to improve the qualitative measures, it may be needed to reconsider the workload norms for faculty members (cost-related metrics). The interrelation of three main assessment criteriaquantitative, qualitative, and costs-related-require a combination of these metrics in the indicators used to measure the faculty performance.

The use of qualitative and cost-related indicators are under researched and need a further analysis, which may be further development of the current research.

Further research can be conducted to account for the differences in the objectives and performance contributions of different departments of a university. For instance, the performance of the faculty of the economic theory department differs from the performance of the foreign languages department faculty. Some departments are expected to contribute to all areas of faculty activities, while others are rather supportive and contribute mainly to the teaching process.

\section{Acknowledgements}

The authors express gratitude to the administration of the Plekhanov Russian University of Economics and its Rector Professor Viktor I. Grishin who had initiated the research and practical application to the system of the faculty performance assessment at the university. The authors also acknowledge the assistance of peers from Russian and foreign universities for their help and openness in sharing their views and experience on the topic of this research.

\section{References}

Blass, E. (2007). Talent management: Maximising Talent for business performance. Chartered Management Institute/Ashridge Consulting.

Clotfelter, C. C. (1996). Buying the best: Cost escalation in elite higher education. Princeton: National Bureau of Economic Research.

Drucker, P. F. (1985). Innovation and Entrepreneurship. New York: Harper and Row.

Foray, D. (2004). Economics of Knowledge. Cambridge: The MIT Press.

Grant, R. M. (1991). A Resource Based Theory of Competitive Advantage: Implications for Strategy Formulation. California Manage, 33.

Khasawneh, S. (2011). Human capital planning in higher education institutions: A strategic human resource development initiative in Jordan. International Journal of Educational Management, 25(6), 534-544.

Levshina, V. V., \& Shimokhina, V. V. (2007). The evaluation of the effectiveness of the quality management system of the educational organization. Problems of the Modern Economy, 23, 18-24.

Loeb, S., Kalogrides, D., \& Béteille, T. (2012). Effective Schools: Teacher Hiring, Assignment, Development, and Retention. Education Finance and Policy. 7(3), 269-304.

Machlup, A. (1996). Production and distribution of knowledge in USA. Moscow: Progress.

Malhotra, Y. (2003). Measuring Knowledge Assets of a Nation: Knowledge Systems for Development. Keynote Presentation at United Nations Advisory Meeting of the Department of Economic and Social Affairs, New York, 4-5 September. Retrieved from http://unpan1.un.org/intradoc/groups/public/documents/un/unpan011601.pdf

McElrath, K. (1992). Gender, career disruption, and academic rewards. Journal of Higher Education, 63(3), 269-281.

Metcalf, H., Rolfe, H., Stevens, P., \& Weale, M. (2005). Recruitment and Retention of Academic Staff in Higher Education. National Institute of Economic and Social Research.

Odden, A. (2011). Strategic Management of Human Capital in Education. New York: Routledge.

Rockoff, J. E., Jacob, B. A., Kane, T. J., \& Staiger, D. O. (2011). Can You Recognize an Effective Teacher When You Recruit One? Education Finance and Policy, 6(1), 43-74.

Schleicher, A. (2006). The economics of knowledge: Why education is key for Europe's success. Brussels: The Lisbon Council asbl: 
Lisbon Council Policy Brief.

Serrat, O. (2010). A primer on talent management. Washington, DC: Asian Development Bank. Retrieved from http://digitalcommons.ilr. cornell.edu/cgi/viewcontent.cgi?article=1112

Shtykhno, D. A. (2012). Theory of human capital as a methodological basis for the managing culture and social culture diversity. Human Capital and Professional Education.

Skorobogatykh, I. I., Selianskaya, I. N., Saginova, O. V., \& Musatova, Z. B. (2012). Development of a complementary team of university professors (using I. Adizes Methodology for the realization of the research project "Development of Plekhanov Russian University of economics professor"). Initiative of XXI century, 2, 56-60.

Tapscott, D. (1997). The digital economy: Promise and peril in the age of networked intelligence. New York: McGraw-Hill. 